\title{
Abundance, richness and diversity of arbuscular mycorrhizal fungi associated with different grass species in semiarid region
}

\author{
HARSH VARDHAN SINGH \\ Grassland and Silvipasture Management Division, ICAR-Indian Grassland and Fodder Research Institute, Jhansi 284 003, Uttar \\ Pradesh, India
}

Received: 18 April 2017/ Accepted: 26 May 2017/ Published online: 31 May 2017

(C) Indian Phytopathological Society 2017

\begin{abstract}
Among herbaceous species, grasses play an important role in livestock feeding in the arid and semi-arid region, especially in water-limited conditions. In arid and semi-arid regions, grasses are more dominated in rangelands and highly dependent on mycorrhization. Root and rhizosphere soil of fifteen grass species were collected to study at Jhansi the root colonization and AM fungal spore population structure. The potential of AM fungal root colonization varied between highest 85.5 percent in Cenchrus ciliaris to lowest 16 percent in Paspalum notatum. AM fungal spore abundance (2394.1/ $100 \mathrm{~g}$ rhizosphere soil) was observed with grass species $C$. ciliaris. A total of 9 AM fungal species isolated and identified. Genus Glomus was the most abundant genus in all selected grass species. There is no clear relationship between root colonization potential and AM fungal spore abundance. All the grass species showed higher AM fungal diversity in their rhizosphere soil. It is clear from this study that grass species are dependent on AM fungal association and had species diversity in the natural ecosystem. Diversity and evenness in AM fungi across the grass species rhizosphere had no any significant relation, however, grass species had higher AM fungi species richness showed less evenness.
\end{abstract}

Keywords: Abundance, diversity, grass species, rhizosphere

Mycorrhizae are highly evolved, the mutualistic association between a group of fungi and plant roots. Arbuscular mycorrhizal fungi (AMF) are ubiquitous soil fungi, form mutualistic symbiosis with a majority of terrestrial plant species (Smith and Read, 2008) and they have a widespread occurrence in the plant kingdom with many benefits to planting growth (Lee et al., 2013), where the host receives mineral nutrients while the fungus obtains photosynthates. AMF are the most influential members of the soil micro-biota which play a key role in tree ecological restoration (Jha et al., 2011; Sharma and Jha, 2014), in root of fern (Ghosh et al., 2012) and crop growth (Karishma et al., 2013; Hindumati and Reddy, 2016) besides nutrient cycling and restoration of degraded ecosystem and sustaining plant diversity and the ecosystem stability. AMF are promising candidates for universal indicators of land management legacies and soil quality degradation (Jansa et al., 2014). In arid and semi-arid regions, grasses are more dominated in rangelands and highly dependent on mycorrhization. Therefore it is essential to understand and quantify the root association and diversity among AM fungal population associated with grass species of this region for better utilization of this symbiotic fungi.

${ }^{*}$ Corresponding author: drharsh2006@ rediffmail.com

\section{MATERIALS AND METHODS}

\section{Study site}

The experimental site was located at Research Farm of Grassland and Silvipasture Management division of Indian Grassland and Fodder Research Institute Jhansi located at $25.5114^{\circ} \mathrm{N} 78.5337^{\circ} \mathrm{E}$ and $275 \mathrm{~m}$ altitudes. Experimentation was done during 2014-15 year. The soil of the site is reddish to brownish in colour coupled with fine gravels. Soil nutrient ranges between nitrogen 140173, phosphorus 5.94-15.84 and potash 57-170 kg/ha. The climate of study site is semi-arid with average annual rainfall of around $850 \mathrm{~mm}$ most of the rainfall received during monsoon season started from end of June to the first week of September. Mean maximum temperature ranges from $42.9^{\circ} \mathrm{C}$ in June to minimum $6.86^{\circ} \mathrm{C}$ in December. Evapotranspiration rate varied from maximum $12.7 \mathrm{~mm}$ in May and minimum $1.7 \mathrm{~mm}$ in December.

\section{Sample collection}

The grass species maintained at $20 \times 50 \mathrm{~m}$ plot size under natural environmental conditions in grass nursery since 32 years were taken under observation. These grasses are being maintained for further evaluation for forage production and ecological adaptation under different soil conditions. A total of 15 grass species as mentioned in Table 1 were selected for the study. Forty 
Table 1. Species richness and diversity index of AM fungi associated with grass species

\begin{tabular}{lllcrc}
\hline Name of grass species & Family & Order & \multicolumn{2}{c}{$\begin{array}{c}\text { Species } \\
\text { richness }\end{array}$} & Species diversity index \\
\cline { 4 - 5 } & & & 6 & 2.24 & Evenness \\
\hline Andropogon gayanus & Poaceae & Poales & 4 & 2.26 & 0.42 \\
Bothriochloa intermedia & Poaceae & Poales & 5 & 2.26 & 0.46 \\
Brachiaria brizantha & Poaceae & Poales & 2.20 & 0.37 \\
Cenchrus ciliaris & Poaceae & Poales & 9 & 2.20 & 0.43 \\
Cenchrus setigerus & Poaceae & Poales & 8 & 2.18 & 0.37 \\
Chloris gayana & Poaceae & Poales & 4 & 2.21 & 0.42 \\
Chrysopogon fulvus & Poaceae & Poales & 6 & 2.23 & 0.40 \\
Heteropogon contortus & Poaceae & Poales & 7 & 2.27 & 0.46 \\
Iseilema laxum & Poaceae & Poales & 6 & 2.13 & 0.39 \\
Panicum maximum & Poaceae & Poales & 5 & 2.26 & 0.49 \\
Paspalum notatum & Poaceae & Poales & 4 & 2.19 & 0.41 \\
Pennisetum pedicellatum & Poaceae & Poales & 6 & 2.22 & 0.43 \\
Sehima nervosum & Poaceae & Poales & 6 & 2.26 & 0.44 \\
Setaria sphacelata & Poaceae & Poales & 5 & 4 & 0.43 \\
Vetiveria zizanoides & Poaceae & Poales & 4 &
\end{tabular}

five samples each of rhizosphere soil and root samples were randomly collected from three different healthy tussocks per species from each plot during the active growth period of grasses (July to September). Root samples were collected for root colonization studies and rhizosphere soil samples were collected for spore population and it structure study. The rhizosphere soil samples were collected from $0-15 \mathrm{~cm}$.

\section{Estimation of AM fungal colonization}

Root and rhizosphere soil samples collected in polythene bags from each randomly selected site separately were sealed and brought to the laboratory. Study of the root samples for AM colonization was performed on the very next day of the collection. Percentage root colonization of AM fungi was done for each grass separately. Roots were kept in running tap water for half an hour to lose the soil adheres to it and washed thrice to remove debris. To determine root percentage colonization, fresh root samples cut into $1 \mathrm{~cm}$ pieces. These small pieces of root were placed in $10 \% \mathrm{KOH}$ solution in beaker separately for each grass sample. The beaker containing pieces of root along with $10 \% \mathrm{KOH}$ boil for about 20 minutes and left for 24 hours. The $\mathrm{KOH}$ was decanted and root pieces were washed with tap water and acidify in lactic acid (5\%) for 2 hours. Thereafter, root samples were put in Trypan blue 0.1\% (Phillips and Hayman, 1970) for 24 hours. These stained root segments put on the slide with lacto-glycerol and observed under the microscope (100 X) (Kormanik and McGraw, 1982). Five slides containing five $1 \mathrm{~cm}$-long root segments for each sample were mounted. The percentage of root colonization was calculated using the following formula:

Root colonization $(\%)=$ Number of arbuscular mycorrhiza positive segments-total number of segments studied $x$ 100.

\section{Estimation and identification of AM fungal spore}

The AM fungal spores present in rhizosphere soil of grasses were extracted following wet sieving method (Gerdemann and Nicolson, 1963). Ten g soil aliquot for each sample suspended in tap water and decanted through sieves size of 300, 150 and 53 micron. Sample sieve collected in water followed by centrifugation in 60 percent sucrose solution (Jenkins, 1964). Spores in sucrose supernatant were collected on filter paper and washed with distilled water. The spores were counted under a stereoscopic microscope (40X). AM fungal spore identified on basis of spore morphology, size colour, spore wall layer and subtending hyphal attachment (Oehl et al., 2011). For AM fungal spore identification each spore having different morphology and colour was mounted on slide and observed using an optical microscope (100 to $400 \mathrm{X}$ ). These observations were matched with the descriptions of individual genera and species of AM fungi (Schubler and Waker, 2010 online available www.amf-phylogeny.com), and information available with International Collection of Vesicular and Arbuscular Mycorrhizal Fungi (http://invam.caf.wvu.edu) along with the original species descriptions.

\section{Diversity studies}

AM fungal diversity studies were carried out from rhizosphere soil samples of each grass species separately collected from three random sites during the study. The following data were collected and analyzed in order to evaluate the species composition and the diversity. Spore density (SD): number of all AM fungal spores per $100 \mathrm{~g}$ air-dried soil. Relative abundance: the number of spores of the AM fungi species as a percentage of the total number of AM fungal spores recorded in the rhizosphere soil. Species richness (SR): the number of AM fungal species per $100 \mathrm{~g}$ air-dried 


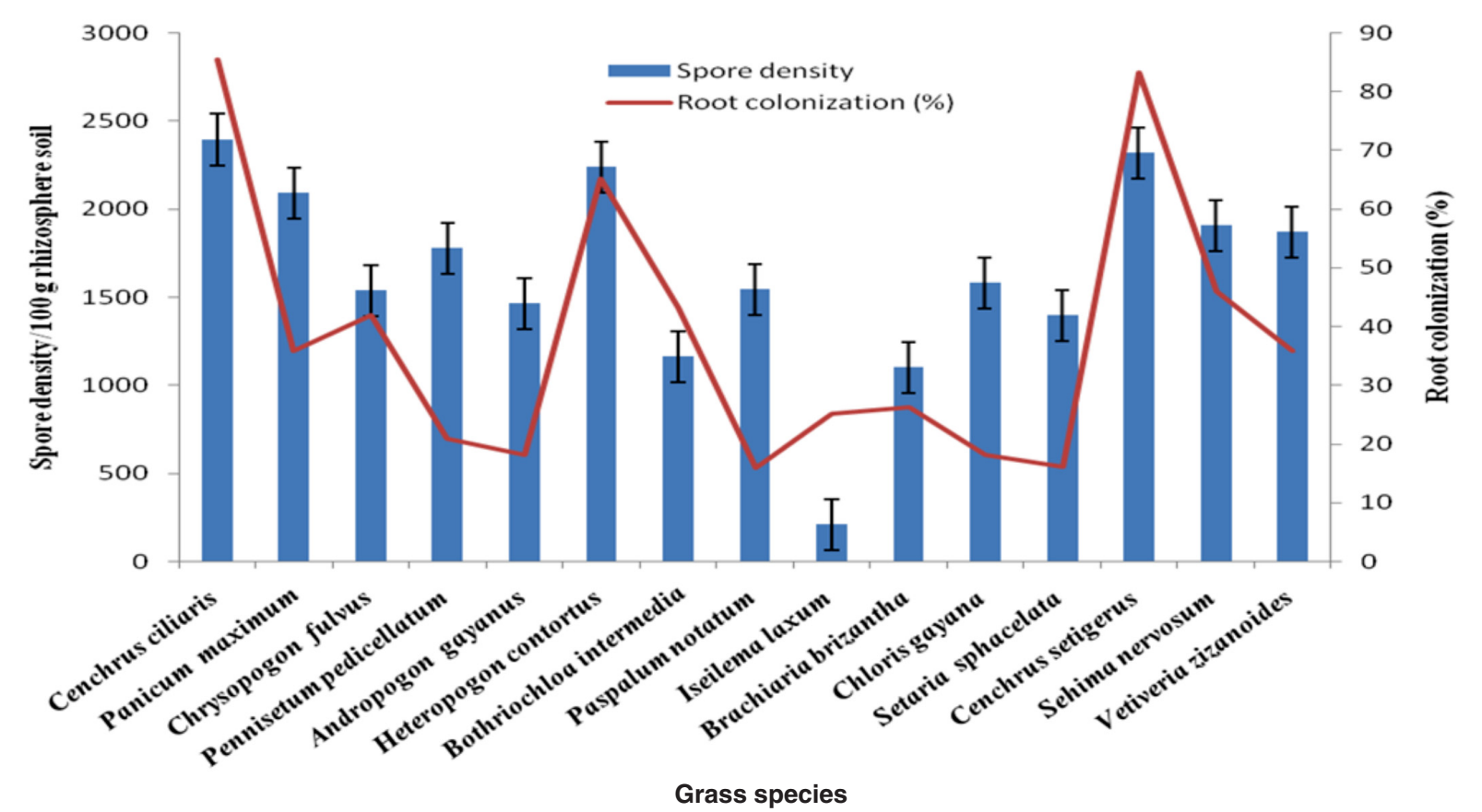

Fig. 1. Spore density and root colonization by AM fungi

soil. Isolation frequency and occurrence frequency of certain AM fungal genus or species in total number of samples is $100 \%$. Species diversity $(H)$ : was calculated by Shannon-Weiner index.

\section{RESULTS}

In the present study, the root of all the grass species had AM fungal colonization, however, the percentage of colonization varied among the species. The percentage of root colonization was high in the roots of Cenchrus ciliaris (85.5\%) followed by C. setigarus (83.2\%) and $H$. contortus (65.3\%). Paspalum notatum was represented the least percentage of root colonization (16\%) (Fig. 1). Spore density per $100 \mathrm{~g}$ rhizosphere soil of fifteen grasses showed that higher spore density in rhizosphere soils was associated with $C$. ciliaris (2394.1) followed by C. setigerus (2316.4), H. contortus (2234.7), P. maximum (2088.5), S. nervosum (1904), V. zizanioides (18684), $P$. pedicellatum (1774.3). The least spore density was observed in I. lexum (208.4) (Fig. 1).

Species richness and diversity index of AM fungi associated with rhizosphere soil of grasses clearly indicates that higher species richness found with rhizosphere soil of $C$. ciliaris (9) followed by $C$. setigerus (8), $H$. contortus (7), five grasses species namely $C$. fulvus, $P$. pedicellatum $A$. gayanus, I. laxum and $S$. nervosum showed species richness (6), three grass species ( $P$. maximum, B. brizantha and $S$. sphacelata) had 5 species richness, while other grasses had least (4) species richness (Table 1).

Species diversity index varied between 2.13-2.27, however, evenness ranged between 0.37-0.49, clearly indicated that grasses had species diversity of AM fungi. As for as relative abundance and isolation frequency of identified AM fungal spore genus Glomus had a higher relative abundance (80.3\%) with 100 per cent isolation frequency. The least relative abundance only 3 percent with isolation frequency 2 percent observed of AM fungal genus Scutellospora However, some of the spores were not able to identify (Table 2). The genus Glomus was found significantly most frequent and abundant AM fungi observed in all the fifteen grasses. Genus Acaulospora and Scutellospora were significantly at par in relative abundance and isolation frequency in rhizosphere soil of all fifteen grass species. It clearly indicates that this genus is more dominant in grassland of the semi-arid region.

\section{DISCUSSION}

AM fungal root colonization in grass species is common and percentage of root colonization depend on grass species root morphology and it exudates released in rhizosphere. Mafaziya and Madawala (2015) observed that percentage root colonization varied among species and the colonization was attributed to host species response to their carbon compound released in the rhizosphere soil. Similar observations were reported by Fall et al. (2015) where root colonization differed with

Table 2. Relative abundance and Isolation frequency of AM fungi

\begin{tabular}{lcc}
\hline AMF species & $\begin{array}{c}\text { Relative } \\
\text { abundance (\%) }\end{array}$ & $\begin{array}{c}\text { Isolation } \\
\text { frequency (\%) }\end{array}$ \\
\hline Acaulospora spp. & 4 & 4 \\
Gigaspora spp. & 11.3 & 85 \\
Glomus spp. & 80.3 & 100 \\
Scutellospora spp. & 3 & 2 \\
Unidentified & 2 & 1 \\
\hline CD 0.05 & 1.86 & 2.21 \\
\hline
\end{tabular}


different species. AM fungal colonization has been reported to depend on soil moisture and nutrient availability, host life cycle and turnover of plant roots (Kirti et al., 2016; Sharma and Jha, 2014). Higher abundance of AM fungal spores associated with grass species was possibly due to higher turnover rates of fine roots and soil biochemical properties in rhizosphere region of particular grass species. Soil type and moisture level also significantly affected the spore population of AM fungi (Shukla et al., 2012).Different grasses have different root morphology and fine root structure one of the most important factors for higher spore density in the rhizosphere of the grass species (Zangaro et al., 2013). Mafaziya and Madawala (2015) reported that natural forest land had higher spore density of AM fungi as this system had less soil disturbance. Difference in sporulation ability and host rhizosphere nutrition composition had a positive effect on species diversity however, species evenness. A total of nine AM fungal species reported from this study while more than 42 species belonging to six AM fungal genus were reported from sunflower rhizosphere soil from Telangana (Hindumathi and Reddy, 2016). Diversity and evenness in AM fungi across the grass species rhizosphere had no any significant relation, however, grass species had higher AM fungi species richness showed less evenness. Beyene et al. (2016) also observed that in different agroforestry system of Sidama had a variable number of AM spore population and which was $1066 \pm 19$.33$100.00 \pm 2.89$ spores per $100 \mathrm{~g}$ of dry soil. The percentage fungal colonization in any individual plant species and spore population in the rhizosphere soils of that species did not correlate to each other. The genus Glomus is known to occur in extremely broad range of habitats with high tolerance of environmental factors. Higher Glomus frequency has been observed from apple orchard plantation (Mehta and Bharat, 2013; Hindumathi and Reddy, 2016).

The present study mainly documents the root colonization and spore density of selected grass species in the arid condition of Jhansi. The diversity of AM fungal population exists in the rhizosphere soil of different grass species in their growing period. However, these grasses evaluated and utilized in different silvopasture systems in diverse land fertility. The effect of different land use pattern and tree component along with different agronomic practices on AM fungal population structure in the rhizosphere needs to be studied.

\section{REFERENCES}

Beyene D, Fassil A and Zebene A (2016). Diversity and Abundance of Arbuscular Mycorrhizal Fungi Under Different Plant and Soil Properties in Sidama, Southern Ethiopia. Adv. Biosci. Bioeng. 4: 16-24.

Fall F, Diouf D, Fall D, Ndoye I, Ndiaye C, Kane A and Ba AM (2015). Effect of arbuscular mycorrhizal fungal inoculation on growth, and nutrient uptake of the two grass species, Leptochloa fusca (L.) Stapf and Sporobolus robustus Kunth, under greenhouse conditions Afr. J. Biotechnol. 14: 2770-2776.

Gerdemann JW and Nicolson TH (1963). Spores of mycorrhizal
'Endogone' extracted from soil by wet sieving and decanting. Trans. Br. Mycol. Soc. 46: 679-684.

Ghosh R, Sengupta S and Bhattacharyya S (2012). Arbuscular mycorrhizal fungi associated with some fern species collected from Kumaon region of western Himalaya Indian Phytopath. 65: 282-285

Hindumathi A and Reddy BN (2016). Dynamics of arbuscular mycorrhizal fungi in the rhizosphere soils of safflower from certain areas of Telangana. Indian Phytopath. 69: 67-73.

Jansa J, Erb A, Oberholzer HR, Smilauer P and Egli S (2014). Soil and geography are more important determinants of indigenous arbuscular mycorrhizal communities than management practices in Swiss agricultural soils. Mol. Ecol. 23: $2118-2135$

Jenkins WR (1964). A rapid centrifugal-flotation technique for separating nematodes from soil. Plant Disease Reporter 48: 692.

Jha A, Kumar A, Kamalvanshi M and Shukla A (2011). Occurrence of arbuscular mycorrhizal fungi in rhizosphere of selected agroforestry tree species of Bundelkhand region. Indian Phytopath. 64: 186-188.

Karishma, Aggarwal A and Anju T (2013). Growth and flower enhancement of Chrysanthemum indicum on inoculation with arbuscular mycorrhizae and other bioinoculants. Indian Phytopath. 66: 57-60.

Kirti S, Sharma R, Dipta B, Pawar R, Kaushal R and Bharat NK (2016). Status of arbuscular mycorrhizae associated with rhizosphere of sweet cherry (Prunus avium) in high hills temperate zone of Himachal Pradesh. Indian Phytopath. 69: 286-289.

Lee EH, Eo JK, Ka KH and Eom AH (2013). Diversity of arbuscular mycorrhizal fungi and their roles in ecosystems. Mycobiology 41: 121-125.

Mafaziya F and Madawala S (2015). Abundance, richness and root colonization of arbuscular mycorrhizal fungi in natural and semi-natural landuse types at upper hantana. Ceylon J. Sci., Biol. Sci. 44: 25-34.

Mehta P and Bharat NK (2013). Arbuscular-mycorrhizal associations with apple plantations of different age groups in Himachal Pradesh. Indian Phytopath. 66: 88-92

Oehl F, Sieverdin E, Palenzuela P, Ineichen K, and Alves da Silva G (2011). Advances in Glomeromycota taxonomy and classification. IMA Fungus: The Global Mycological Journal 2: 191-199.

Phillips JM and Hayman DS (1970). Improved procedures for clearing roots staining parasitic and vesicular-arbuscular mycorrhizal fungi for rapid assessment of infection. Trans. Br. Mycol. Soc. 55: 158-161.

Sharma B and Jha DK (2014). Arbuscular mycorrhizal fungal association in some commonly occurring economically important plants of Kaziranga National Park, Assam, India. Indian Phytopath. 67: 243-251

Shukla A, Kumar A, Jha A and Tripathi VD (2010). Effect of soil moisture on growth and arbuscular mycorrhizal colonization of crops and tree seedlings in alfisol. Indian Phytopath. 63: 411-417.

Smith SE and Read DJ (2008). Mycorrhizal Symbiosis. Academic Press, Amsterdam, The Netherlands, 3rd edition pp 800.

Zangaro W, Rostirola LV, de Souza PB, Alves RA, Lescano LEAM, Rondina ABL, Nogueira MA and Carrenho R (2013). Root colonization and spore abundance of arbuscular mycorrhizal fungi in distinct succesional stages from an Atlantic rainforest biome in southern Brazil. Mycorrhiza 23: 221-233. 